\title{
Train-the-Trainers: Implementing Outcomes- based Teaching and Learning in Malaysian Higher Education
}

\author{
JOHN BIGGS ${ }^{1}$ \\ Honorary Professor of Psychology \\ University of Hong Kong \\ \& Honorary Associate \\ School of Psychology \\ University of Tasmania \\ jbigss@bigpond.com ${ }^{1}$ \\ CATHERINE TANG \\ Educational Consultant
}

\begin{abstract}
The decision by the Minister of Higher Education, that Malaysian post-secondary institutions should move to outcomes-based teaching and learning (OBTL), involves a change in teaching in over 1,000 institutions. This massive changeover would be accomplished using the "Train-the-Trainers" model in a series of workshops. We are proud to play a role in the first of these Trainthe-Trainers programmes. In this article we explain how OBTL was conceptualised in the constructive alignment model, and how this first programme was structured. The major outcome was that each trainer would devise their own training programme to suit the conditions of their institution. The results were impressive but there were some difficulties; mainly to do with limiting the number of intended learning outcomes to a workable number, that would need to be addressed in order to achieve optimal outcomes.
\end{abstract}

\section{INTRODUCTION}

The Higher Education Learning and Teaching Initiative (HELTI) was launched by the Minister of Higher Education, YB. Dato' Seri Mohamed Khaled Nordin on November 23, 2009. HELTI uses the Train-the-Trainers model, by which 1,035 handpicked Master Trainers will acquire the skills and knowledge needed to provide the staff development needed for over 56,000 academics nationwide. 
The first Train-the Trainers programme, "Quality Teaching for Learning", was held on 23 - 25 February, 2010, and was introduced by Dato' Professor Dr. Ahmad Zainuddin, Director of Higher Education Leadership Academy (AKEPT) Malaysia. The programmes organized by AKEPT's Centre for Learning and Teaching are part of the National Higher Education Strategic Plan to improve the quality of teaching and learning in higher education institutions. The "Quality Teaching for Learning" programme was designed to provide participants with the relevant expertise to design an in-house training programme in outcomes-based learning and teaching in their own institutions using the constructive alignment model.

\section{OUTCOMES-BASED TEACHING AND LEARNING}

(1) Outcomes-based teaching and learning (OBTL) requires a major shift in perspective, from traditional methods of teaching that rely on the transmission of content to students, to engaging students in actively constructing their own knowledge.

Traditional teaching starts from the perspective of the teacher: "What topics or content do I teach?" Traditional teaching methods are expository, and the assessment checks how well the message has been received and understood - hence the common use of lectures, demonstrations, tutorials for clarification, and exams that rely on reporting back.

In outcomes-based teaching the question is not "What topics do I teach?", but "What do I want my students to be able to do after they have learned what is in the curriculum?" For example, "we don't teach psychology to student teachers to see how much they can tell us about the psychology we have taught them, but how have their teaching decisions been changed as a result of having learned psychology. Thus, in OBTL, we go further than specifying the topics to be taught; we define the outcomes we want our students to achieve. Doing this swings our perspective around $180^{\circ}$, from a teacher-centred to a student-centred approach to teaching.

The model of OBTL we are dealing with here is called "constructive alignment", first described in Biggs (1996) and later elaborated with details for implementation, with examples, in Biggs and Tang (2007). Constructive alignment goes further than specifying the intended learning outcomes; it also specifies how those outcomes may best be achieved by engaging students in appropriate learning activities. The "constructive" part is taken 
from the constructivist learning theory that emphasises that learners construct their knowledge through their own activities; teachers do not "transmit" knowledge, learners have to learn through their own activity. The "alignment" part refers to aligning the students' learning activities and the assessment tasks to the intended outcomes. The concept of alignment originally arose in the context of criterionreferenced assessment, which states that assessment should be about how well the student meets previously stated criteria or standards of learning. Here we extend the notion of alignment to teaching as well. In other words, we don't just "teach", with lecturing as the default, but we design activities for our students that will help them to achieve the intended outcomes more effectively.

These ideas are captured by Thomas Shuell (1986), who summarized teaching as follows:

\begin{abstract}
If students are to learn desired outcomes in a reasonably effective manner, then the teacher's fundamental task is to get students to engage in learning activities that are likely to result in their achieving those outcomes. ... It is helpful to remember that what the student does is actually more important in determining what is learned than what the teacher does. (p. 429)
\end{abstract}

This statement seems so obvious, but hidden inside there is a widely applicable three-stage model of outcomes-based teaching and learning:

1. Define what students are supposed to do as a result of having been taught a topic; these are the intended learning outcomes

2. Engage them in learning activities that are most likely to help them achieve those outcomes.

3. Assess to see how well they have achieved the intended outcomes.

Constructive alignment fills in those details. We shall summarise the main stages.

\title{
Defining the Intended Learning Outcomes
}

The intended learning outcomes (ILOs) are based on the assumption that when students "really" understand something they see those aspects of the world to which the topic applies differently, and 
therefore they behave differently towards it in "performances of understanding", as Gardner (1993) puts it. For example, even a subject like history is not just about learning narratives about the past and testing to see how well students have understood them. That is an important first step, but what we should really want is to see how students can use that knowledge to see how they may interpret the present more effectively, and to plan for the future without repeating past mistakes.

The challenge for teachers in any subject is thus to decide in what ways they want their students to transform their topic knowledge into appropriate action. Examples would be: solving problems in a given area, making and testing hypotheses, analyzing -complex data, and so on. Each topic taught has its own performances of understanding. As teachers, we need to be clear about what these performances are for the content we teach.

Accordingly, the intended learning outcomes need to be formulated so that they include not only the content that students are intended to learn, but what they are supposed to do with the content, and to what level. In writing the intended learning outcome then, we need to specify what it is the student has to do by specifying a verb, such as "explain" or "apply", and the content and context in which the student has to do it.

We have been talking so far about intended learning outcomes. However, we must allow for desirable but unintended learning outcomes, for these can be as important, and sometimes more important, than those outcomes that are intended. If Alexander Fleming had only restricted himself to his intended outcomes he would not have discovered penicillin. Accordingly, some at least of our assessment tasks should allow students to display performances of understanding that they might consider relevant but that we hadn't thought of.

\section{The Nature of Understanding}

All teachers would say that they "teach for understanding" but that could mean a whole range of levels of understanding. We need to be rather more precise about what level of understanding we intend to achieve in our learning outcomes, and to do this we can use the SOLO taxonomy (Biggs \& Collis, 1982).

SOLO is an acronym for "Structure of Observed Learning Outcome" and it refers to the fact that when something is learned it grows in complexity: 
1. One or a few aspects of the task are learned (unistructural);

2. More and more aspects are acquired but they are not interrelated or integrated (multistructural);

3. The hitherto unrelated aspects of the task become related to form an integrated whole (relational);

4. The integrated whole is generalised to new, untaught and more abstract domains (extended abstract).

These stages occur when a person first approaches a learning task; learning to use a new digital camera, say. The manual usually advises the beginner to set the camera on "auto" and use it as point-and-shoot only. Then, as need and confidence rise, more and more operations are acquired (multistructural) but genuine mastery of the camera is not acquired until the settings are coordinated (ISO, shutter speed, aperture, light setting, etc.) to suit a particular shot - this is the relational level of photographic skills. Extended abstract operations would go beyond the manual, leaving it to the photographer's creativity to produce genuinely original results.

SOLO can be used at all phases of teaching: for defining the intended outcomes of teaching a topic or course in either quantitative or qualitative terms, for designing the teaching and learning activities appropriate for achieving those outcomes, and for assessing how well the student has learned what is intended to be learned. It is particularly useful in constructive alignment to decide on the level of complexity of the learning verb(s) to be written in the intended learning outcomes, and to judge the quality of unintended outcomes should they arise. Here are some typical learning verbs at various SOLO levels:

Table 1

Some Learning Verbs at Various SOLO Levels

Unistructural memorize, identify, recognize, count, define, draw, find, label, match, name, quote, recall, recite, order, tell, write, imitate

Multistructural classify, describe, list, report, discuss, illustrate, select, narrate, compute, sequence, outline, separate 
Relational apply, integrate, analyse, explain, predict, conclude, summarize (précis), review, argue, transfer, make a plan, characterize, compare, contrast, differentiate, organize, debate, make a case, construct, review and rewrite, examine, translate, paraphrase, solve a problem

Extended abstract theorize, hypothesize, generalize, reflect, generate, create, compose, invent, originate, prove from first principle, make an original case, solve from first principle

Each such verb addresses a different level of understanding "performatively", as Gardner put it. The learning outcomes are defined qualitatively in terms of lower or higher cognitive learning activities that can drive decision-making. Commonly used verbs such as "understand", "comprehend" or "appreciate" do not nominate a particular or operational target to achieve: you can say you can "understand" something at all SOLO levels.

For example, suppose that an intended learning outcome (ILO) in a course on psychology for teachers is stated as: "The student will understand expectancy-value motivation theory". Does this mean that the student is able to:

Write a text-book definition of the expectancy-value theory?

Explain how it works in the student's own words?

Watch a video of a teacher-student interaction and be able to predict what is likely to happen to the student's motivation afterwards?

Reflect on the student's own teaching to illustrate that a problem that had occurred could be accounted for and rectified by applying the expectancy-value theory?

All the above are examples of "understanding" at some level or other. Clearly, we need to pin down the level of understanding we want when stating the ILO. A recent adaptation of the Bloom taxonomy (Anderson \& Krathwohl, 2001) also provides hierarchies of verbs that can be used to address various levels of understanding and teachers may find both the SOLO and Bloom provide useful prompts for selecting verbs when writing outcome statements. 
Table 2

Some ILO Verbs from Bloom's Revised Taxonomy

Remembering define, describe, draw, find, identify, label, list, match, name, quote, recall, recite, tell, write

Understanding classify, compare, exemplify, conclude, demonstrate, discuss, explain, identify, illustrate, interpret, paraphrase, predict, report.

Applying apply, change, choose, compute, dramatize, implement, interview, prepare, produce, role-play, select, show, transfer, use

Analysing

analyze, characterize, classify, compare, contrast, debate, deconstruct, deduce, differentiate, discriminate, distinguish, examine, outline, relate, research, separate organize, structure

Evaluating appraise, argue, assess, choose, conclude, criticize, decide, evaluate, judge, justify, predict, prioritize, prove, rank, rate, select, monitor

Creating

construct, design, generate, hypothesise, invent, plan, produce, compose, create, invent, make, perform, plan, produce, design, develop,

Source. Anderson and Krathwohl (2001).

Although the original Bloom Taxonomy was not based on research on student learning itself, as was SOLO, but on the judgments of educational administrators, it can nevertheless be a useful adjunct for suggesting verbs for a range of learning activities.

In writing outcome statements, it is important to distinguish between the kinds of knowledge to be addressed:

1. Declarative knowledge, which is knowledge about the discipline or topic. Typical verbs: "classify", "explain", "compare and contrast".

2. Functioning knowledge, which is knowledge that drives decision-making and informs action. Typical verbs: "apply, "solve", "design", "reflect". 
Whereas declarative knowledge is second hand to the learner, functioning knowledge is based on, and acquired through, personal experience. Today, when vocational and professional education play a larger part than hitherto in higher education, the ultimate intended outcomes are that students will be practitioners, carrying out procedures and making decisions as to the conditions under which alternative courses of action may be made. Despite that, however, much university teaching is concerned predominantly with declarative knowledge, whereas especially in professional education, knowledge needs to directly inform action as functioning knowledge. Educational psychology is taught in order to help future teachers make more informed and better decisions, not to enable them to write essays or exam questions about the psychology they had learned. The use of verbs, such as apply, reflect, design and so on, help avoid too strong an emphasis on declarative knowledge. Certainly a base of declarative knowledge of psychology is essential, but it should not be the only sort of knowledge that is fostered and assessed. In writing ILOs for a course, then, it is important to see that the appropriate kind of knowledge is addressed.

One objection to outcomes-based education is that describing and teaching to sets of outcomes is too restrictive (Jervis \& Jervis, 2005). This may be the case when the outcomes are low level, as in competency-based education as used in vocational training, but where verbs such as hypothesize, create, design, or reflect are used, the outcomes are open-ended. They positively challenge students to be creative, rather than "spell the death of originality and serendipity" as Jervis and Jervis somewhat carelessly accused constructive alignment of doing. The fact that we allow for unintended outcomes is the very opposite of restrictive teaching.

\section{Choosing Teaching/Learning Activities}

The teaching/learning activities (TLAs) focus on activating the verbs in the intended learning outcome statements. It is evident that the most efficient way the student can achieve the outcomes is to enact the same verbs that the outcomes themselves require. One learns to drive a car by driving, not by listening to lectures on driving.

If the intended outcome statement refers to explaining a concept, say, the appropriate learning activity is to require the students to explain the concept; they shouldn't be taking notes while 
a teacher does the explaining. Students could do their explaining in pairs, even in large classes, each assessing the other's explanation using rubrics for assessing the explanations; the students thus do the explaining, and receive immediate feedback on how well they do it through peer-assessment. In this way they learn how to make a good explanation as well as reinforce the content of what it is that is being explained (generic rubrics for assessing quality of explanation are given in Table 3) .

TLAs addressing complex outcomes may need supplementary, or enabling, TLAs. For example, a task may be broken into component parts in order to practise an aspect of the task that is currently weak. If the intended outcome is that students solve clinical problems, it may be necessary for students to first acquire relevant background knowledge or skills before tackling the main task of problem-solving.

A problem is that the large rooms in which teaching takes place are called "lecture theatres", which strongly implies that the teaching to take place there is by teachers talking and students listening and taking notes. However, a lot of different TLAs can take place in even large classes - the "explain" example using peer teaching and peer assessment is an example. There is also the assumption that teaching, and therefore learning, can only take place in the classroom, which rules out a lot of TLAs; often the most important ones for functioning knowledge and higher order ILOs. In professional education, the richest learning contexts will be the workplace, not the classroom. The most important learning of all - lifelong learning - is by definition learning that takes place outside the classroom without any teacher at all and for that ILO to be achieved the learner must experience independent learning situations.

\section{Designing Assessment Tasks and Grading Procedures}

The assessment tasks likewise address the same verbs as are stated in the intended outcomes. When the assessment task is the TLA itself, alignment is perfect. If the verb is explain, the assessment is in terms of how well the explanation is carried out. In the explain example, for instance, the students learned how to explain the topic content by using peer-teaching and peer-assessment; the teacher could then use the same rubrics to assess the students summatively as the 
students used formatively. The rubrics would allow assessment at different grade levels (A, B, C, D), or even for awarding quantitative percentage "marks". Table 3 gives rubrics for assessing the verb "explain" in four levels of quality, which as may be seen, have been designed with SOLO in mind. However, the levels can be converted into a quantitative scale for ease of combining assessment results, as suggested in the second row of the table.

As the intended outcomes are stated in qualitative terms, the most appropriate form of assessment is also qualitative, where the task is assessed as a whole, not analytically. A common way of assessing is analytically, that is by awarding marks for this aspect and for that aspect of the assessment task. The effect is that a student could fail a section of the task but still average enough marks to pass. Analytic assessment is helpful to give formative feedback on aspects of the total performance that might need strengthening, but summative assessment needs to be in terms of the total performance, requiring judgement of a student's performance on an assessment task against assessment criteria or rubrics (Taylor, 1994).

Timed examinations, multiple-choice tests and other closed methods of assessment, as are traditionally used, can serve for assessing "basics", but some assessment tasks need also to allow for unintended or unforeseen but desirable outcomes. Trying to find out what students have learned by asking only closed questions is like fishing with a large meshed net and then concluding that smaller fish do not exist because you haven't caught any.

High level verbs in the ILO, such as hypothesize, reflect, solve unseen problems, create, leave the outcome quite open, so the assessment task needs to allow for the unexpected. Assessment by portfolio requires students to place samples of the performances that they think are evidence that they are achieving the intended learning outcomes of the course, together with their rationale for why they think they do, thus allowing assessment of high level verbs including reflective self-assessment.

\section{Generic Learning Outcomes}

The Ministry of Higher Education requires programmes to address nine generic learning outcomes, including, apart from knowledge and skills, lifelong learning, communication skills, critical thinking and problem-solving, amongst others. OBTL is a useful structural 
device for seeing that these are appropriately built into programmes and courses, and to address them. For example, lifelong learning essentially means that students are to learn to take control over their own learning after they have left formal education. Teaching should encourage this by making sure the students can teach and assess themselves; that they understand the learning outcomes with sufficient clarity that they can make them their academic destination; that students use the teaching/learning activities, and other learning activities of their own creation, as their means of getting there; and obtain feedback from self-assessment as their road map. An important outcome that addresses lifelong learning is thus that students monitor their own learning and become self-sufficient in learning after the institutional structures for supporting learning have been outgrown and removed.

Although learning outcomes are expressed generically, then, to be usable they need to be linked to outcomes at the programme level. The course-intended learning outcomes then address the programme-intended outcomes as appropriate to the course content. In this way, there is alignment between courses and programmes, and between programmes and the institution's chosen set of generic learning outcomes, which makes - or should make - the whole institution an integrated working system. In that case, the same arguments about reflective practice at the teacher level apply to the institution, with policies and a culture that support teaching (Biggs, 2001). For example, a requirement that grades follow a predetermined distribution simply means that constructive alignment, or any form of criterion referencing, cannot work.

Effective teaching needs continually to adapt to changing circumstances by means of reflective practice (Schon, 1983). Reflective practice involves monitoring one's performance to spot problems and to apply theory in order to generate solutions. Reflective practice is especially important in implementing constructive alignment because, as a total system, changes in one component will require adjustments throughout the system. One needs to be on the continuing alert for rethinking outcome statements if things do not go as hoped for, for adjusting teaching/learning activities and assessment tasks and/or their rubrics. Ideally, constructive alignment should be implemented in an action research framework to ensure quality enhancement of teaching and learning (Biggs \& Tang, 2007; pp. 249-251). 


\section{THE “QUALITY TEACHING FOR LEARNING” PROGRAMME TO TRAIN-THE-TRAINERS}

We have had experience before with implementing constructive alignment (CA) on a classroom-wide basis and on an institution-wide basis. Working at the institutional levels is much more challenging because we are dealing with hundreds of courses and teachers. But here in Malaysia, we are looking at implementation on a nationwide basis - a daunting prospect indeed. AKEPT are handling this onerous task with the idea of "Train-the-Trainers", that is, training first those who in turn will train the actual teachers. The programme we conducted on February 23-5, 2010, was thus for staff developers who would then go back to their institutions and train their own staff. This concept has considerable advantages:

We had 140 at our workshop with sometimes 4 or 5 from the same institution, which meant that a capable team would be equipped for training a whole institution. This means that this three-day programme alone would result in around 30 institutions implementing constructively aligned OBTL.

2. We were dealing with experienced staff developers, making our task much easier than if we were dealing directly with teachers.

The teachers would be trained in their own institutions by their staff developers. Some teachers resent it if outsiders come to their institution to tell them how to teach, as if what they are doing is wrong and it needs outsiders to set them straight. This is not the case at all of course, but that can be a perception, which is less likely in the Train-the-Trainers scenario.

In consultation with AKEPT, we designed a two and a half day programme with the following intended outcomes:

1. The trainers need to understand constructive alignment to the point where they can apply the principles in the intended way. We sent out pre-reading material explaining the concept of constructive alignment. The first morning of the programme was a seminar on the key points of constructive alignment followed by discussion. The idea of this was to provide the trainers with an experience, learning about CA, that they would be creating back in their own institutions. On the first 
day of the programme, we found that many people seemed uneasy. We only found out why on the last day, as discussed below.

2. The trainers need to identify factors affecting implementation on an institutional level. It is one thing for teachers to be clear about CA for themselves, but they will be operating in institutions with traditions, practices, and personnel procedures that have a bearing on how effectively CA can be implemented. For example, CA can't work if norm-referenced assessment is required, while staff assessment for promotion using teacher-feedback questionnaires that focus on clarity of lecturing strongly discourages teachers from using more effective TLAs. A seminar on these issues was held in the afternoon of the first day.

3. The trainers need to learn to write Intended Learning Outcomes (ILOs), design Teaching/Learning Activities (TLAs) and Assessment Tasks (ATs) for themselves, before they can teach others. The second day comprised a 6-hour workshop with activities designed to address the required application needed for the three areas of writing ILOs, and designing TLAs and ATs.

4. The trainers need to design staff development programmes for their own institutions. Once they are able to write ILOs, and design teaching/learning activities and assessment tasks, the trainers need to develop staff development programmes for their own staff and work out strategies of implementation such that teachers and departments can become self-sufficient in implementing $\mathrm{CA}$ in their own courses and programmes. This was the major intended outcome of the programme: that all trainers design their own staff development programmes for use in their own institutions. Where possible, trainers were grouped in teams from the same institution in a three- hour workshop on the morning of day three.

5. The trainers need to maintain a portfolio of items in order to provide formative assessment on the effectiveness of the staff development programme, and to provide a structure for continuing monitoring the implementation of OBTL in their own institutions. The aims of the portfolio were to help participants reflect on their effectiveness as trainers and staff developers in implementing constructive alignment in their own institutions, to keep track of the on-going progress of the staff development programme and to identify areas for further 
improvement of the implementation of OBTL, and to provide feedback to the AKEPT Centre for Learning and Teaching so that further support may be provided to the trainers. Items to be included in the portfolio were suggested along with peer assessment by colleagues in the same institution.

6. The trainers and senior administrators need to review institutional policies so they are compatible with constructive alignment. Some policies, such as grading on the curve, prevent implementation of constructive alignment. Quality enhancement procedures, such as reflective practice and action research, are to be encouraged.

All these activities were successfully implemented, except the last which was left to individuals in their own institutions.

The main outcome of the Train-the-Trainer programme was (4) above: staff developers developing programmes they would implement in their own institutions. We were very impressed with the results. However, it was at this session that some difficulties that had been worrying many of the trainers earlier came to light and were clarified.

\section{SOME ISSUES THAT NEED TO BE CLARIFIED}

\section{A Topic-Based Curriculum}

Some participants started with the topics to be taught and then converted them into outcomes. In delivering a course, there might be say 10 topics to be taught but in writing several outcomes for each topic, a massive set of 30 or more outcomes would be created, which is unmanageable; you can't align TLAs and ATs to 30 outcomes! In our experience, a semester-long course would realistically have about 5 or 6 outcomes, no more.

There might well be 10 topics in the curriculum for a course, but ILOs can be so designed that group topics are addressed by one ILO. For example here are the ILOs for the course "Engineering Principles and Design" (see Biggs and Tang, 2007, pp. 295-299 also gives the TLAs and ATs for the course).

"Upon successful completion of this course, students should be able to: 
ILO1. Apply the principles of mechanical kinetics to single degree of freedom vibration systems.

ILO2. Outline the fundamental theory of friction and wear and its applications in engineering.

ILO3. Describe the basic theories of fluid mechanics and heat transfer.

ILO4. Apply the basic engineering mechanics principles to the design and implementation of a simple engineering system (such as a projectile machine) and the evaluation of its performance.

ILO5. Work effectively as a team member in a small-scale engineering project."

Thus, ILOs are more like the sub-themes of a course, each of which could be applicable to several topics. In the example here, there is a good mix of declarative and functioning knowledge ILOs and each would be relevant to more than one, and sometimes several, topics.

\section{Effects of the Bloom Taxonomy}

The Ministry has recommended that all programme outcomes must be balanced in terms of the three domains addressed in Bloom's taxonomy of educational objectives: the cognitive domain (Bloom, 1956), the affective domain (Krathwohl, Bloom and Masia, 1973), and the psychomotor domain (unfinished by Bloom but see Simpson, 1972). Somewhere along the line the misunderstanding seems to have arisen that a course must address all three domains. However, the affective domain and/or the psychomotor domains may not be applicable to all courses and to include them not only multiplies the number of outcomes unnecessarily, but they are irrelevant to the course. At the programme and graduate outcome level all three domains may be relevant, and it is useful to have Bloom remind us to think about this possibility, but they certainly should not be prescribed in fixed proportions. The proportion of different kinds of outcome domain should not be ordained before designing ILOs, although bearing these different domains in mind can be a useful reminder that they might need to be taken into account - but only if course and programme designers think that they are relevant.

We understand that the official Ministry's position is that the three domains, cognitive, affective and psychomotor, should be addressed in the nine HEI learning outcomes and that the learning 
outcomes are addressed in a programme, but not in each course. However, some teachers told us that courses had been rejected by the course approving body because they didn't address all three domains. There is clearly a disconnect here, but it is not up to us to say where the problem lies - we only know that the problem exists.

Another use of Bloom is in the latest version (Anderson and Krathwohl 2001), which as we have seen in Table 2 is useful for providing a range of possible verbs for writing ILOs.

\section{SUMMARY AND CONCLUSIONS}

We have described here a programme, "Quality Teaching for Learning", that was the first to address the Ministry of Higher Education's initiative to implement outcomes-based teaching and learning (OBTL) in Malaysian higher education institutions. The structure used was that of Train-the-Trainers, a cost-effective way of reaching out to Malaysia's numerous institutions, the model for OBTL being that of constructive alignment.

Constructive alignment makes explicit not only the content topic but what the student is expected to do with that content in the form of intended learning outcomes, and engages students by designing teaching/learning activities that are likely to encourage the - cognitive processes needed to achieve those outcomes. Statements - of outcomes contain a verb or verbs, such as apply, reflect, explain, and so on, that articulate clearly what level of understanding is intended for the students in the course in question, and the learning activity required to best achieve the intended outcomes. The teaching context is designed precisely to require the students to enact those verbs, and the assessment tasks to allow teachers and students to see how well the intended outcomes - and desirable if unintended outcomes - have been achieved.

The "Quality Teaching for Learning" Programme for training the trainers was designed to achieve the following intended outcomes:

- The trainers need to understand constructive alignment to the point where they can apply the principles in the intended way.

- The trainers need to identify factors affecting implementation on an institutional level.

- The trainers need to learn to write Intended Learning Outcomes (ILOs), design Teaching/Learning Activities 
(TLAs) and Assessment Tasks (ATs) for themselves, before they can teach others.

- The trainers need to design a staff development programme for their own institutions.

- The trainers need to maintain a portfolio of items in order to provide formative assessment on the effectiveness of the staff development programme, and to provide a structure for continuing monitoring the implementation of OBTL in their own institutions.

The trainers and senior administrators need to review institutional policies so that they are compatible with constructive alignment.

In the course of the workshop some misconceptions were uncovered, including the need to think of the curriculum as outcomesbased rather than topic-based, and to avoid any stipulation at the course level that all of the cognitive, affective and psychomotor domains of Bloom's taxonomy have to be addressed.

However, we must say that the programme has been successful in achieving the intended outcomes, and we are honoured to be part of this important initiative.

\section{REFERENCES}

Anderson, L.W., \& Krathwohl, D.R. (2001). A taxonomy for learning, teaching, and assessing: A revision of Bloom's taxonomy of educational objectives. New York: Addison Wesley Longman.

Biggs, J.B. (1996). Enhancing teaching through constructive alignment. Higher Education, 32, 1-18.

Biggs, J.B., (2001). The reflective institution: Assuring and enhancing the quality of teaching and learning. Higher Education, 14, 221-238.

Biggs, J.B., \& Collis, K.F. (1982). Evaluating the quality of learning: The SOLO taxonomy. New York: Academic Press. Biggs, J.B., \& C. Tang. (2007). Teaching for quality learning at university. Maidenhead, Berks.: Open University Press/ McGraw Hill Education.

Bloom, B.S. (Ed.). (1956) Taxonomy of educational objectives: Handbook I, Cognitive domain. New York: Longman. 
Gardner, H.W. (1993, July). Educating for understanding. The American School Board Journal, 20-24.

Jervis, Loretta M., \& Jervis, L. (2005). What is the constructivism in constructive alignment? http://www.bioscience.heacademy. ac.uk/journal/vol6/Beej-6-5.aspx_

Krathwohl, D. R., Bloom, B. S., \& Masia, B. B. (1973). Taxonomy of educational objectives, the classification of educational goals. Handbook II: Affective domain. New York: David McKay.

Schon, D.A. (1983). The reflective practitioner: How professionals think in action. London: Temple Smith.

Shuell, T.J. (1986). Cognitive conceptions of learning. Review of Educational Research, 56, 411-436.

Simpson, E. J. (1972). The classification of educational objectives in the psychomotor domain. Washington, DC: Gryphon House.

(1) Taylor, C. (1994). Assessment for measurement or standards: The peril and promise of large scale assessment reform. American Educational Research Journal, 31, 231-262. 


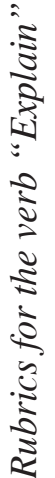

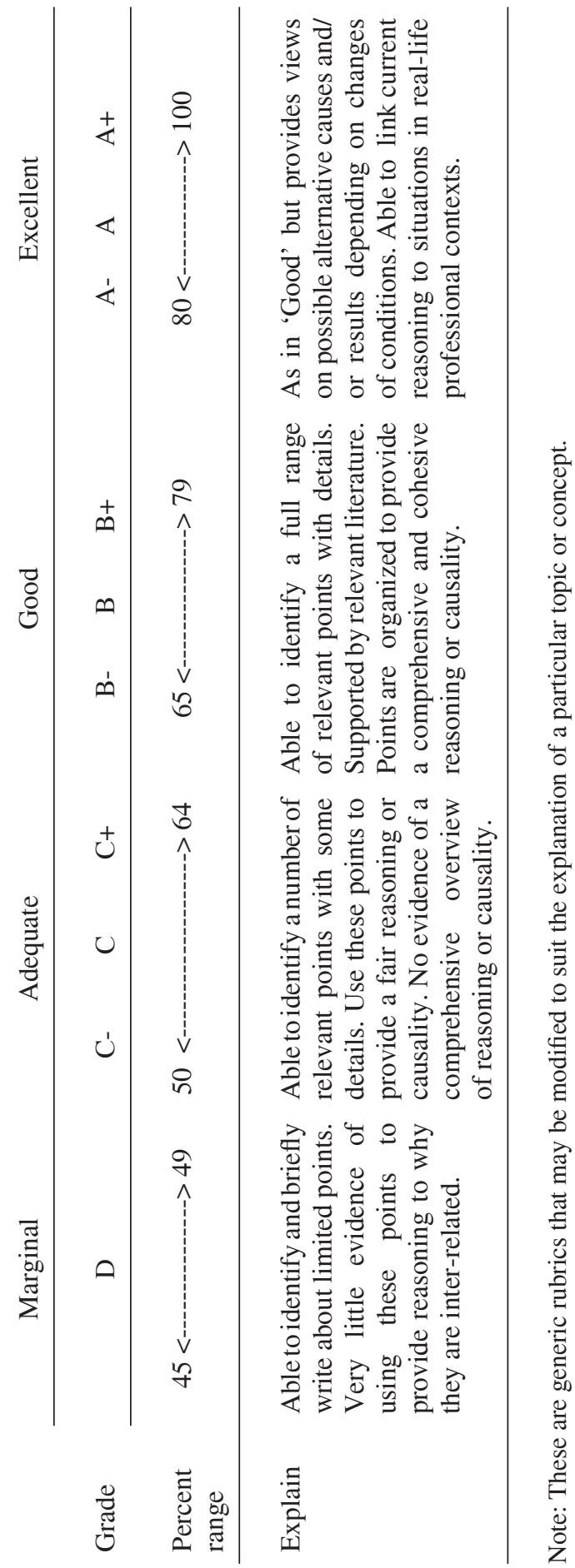




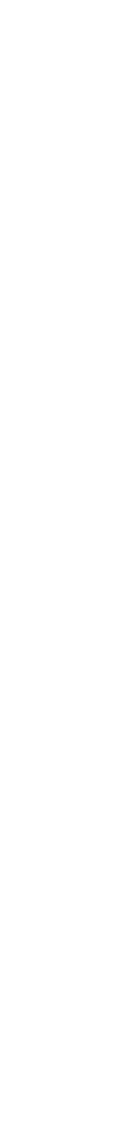

